\title{
Synbiotic Yogurt Supplemented with Ocimum sanctum Essential Oil
}

\author{
Santosh Anand ${ }^{1 *}$, Manju Gaare ${ }^{2}$, Priyanka Saini ${ }^{1}$, Arun Beniwal ${ }^{1}$ and \\ Chand Ram Grover ${ }^{1}$
}

${ }^{1}$ Bioremediation Research Laboratory, Dairy Microbiology Division, ICAR-National Dairy Research Institute, Karnal-132001, Haryana, India

${ }^{2}$ Department of Dairy and Food Microbiology, GN Patel College Dairy Science and Food Technology, Sardarkrushinagar Dantiwada Agricultural University, Gujarat, India

*Corresponding author

\section{Keywords}

Yoghurt, Prebiotic, Probiotic, Essential oil, Symbiotic

Article Info

Accepted:

10 February 2018

Available Online:

10 March 2018

\section{A B S T R A C T}

The present investigation was focused primarily to develop synbiotic herbal yoghurt incorporating Ocimum sanctum essential oil (EO). Prebiotic was selected on the basis of specific growth rate $(\mu)$ of cultures. EO concentration was optimized on the basis of its compatibility of culture and sensory properties. Investigations on effect of prebiotics (inulin and maltodextrin) on growth kinetics of probiotic cultures indicate that former enhanced change in $\log$ count $/ \mathrm{ml}$ and specific growth rate $(\mu)$ faster than maltodextrin at $3 \%$ level. Change in log count and specific growth rate were observed to the tune of 1.78 $\mathrm{CFU} / \mathrm{ml}$ and $0.683 \mathrm{~h}^{-1}$ at $3 \%$ inulin in comparison to $1.42 \mathrm{CFU} / \mathrm{ml}$ and $0.545 \mathrm{~h}^{-1}$ of maltodextrin at above level during incubation period in case of L. bulgaricus LB-2. Almost similar trend was obtained in case of $S$. thermophilus ST-1 for both prebiotics. Culture inoculum at rate of $1 \%$ and $\mathrm{EO}$ at concentration $0.5 \mu \mathrm{L} / \mathrm{ml}$ was found compatible with yoghurt culture on the basis of sensory, physiological and microbiological quality. The developed product was assessed for shelf life quality parameters upto 21 days. The developed product was judged suitable for consumption with acceptable sensory attributes and viable probiotic counts $\left(10^{8}-10^{9} \mathrm{cfu} / \mathrm{ml}\right)$ till 15 days of storage. The developed product possesses antioxidative activity and phenol content of $763.8 \mu \mathrm{M}$ trolox equivalent/L and 7 mg GAE/100 ml respectively. Further research is needed by employing clinical trials to substantiate in vitro data. As a value added synbiotic herbal product, it may have great potential for commercialization.

\section{Introduction}

Dairy foods have been consumed since ages as almost complete foods to meet body energy requirements. Dairy foods especially fermented products are highly consumed by people of all age groups and have been choice of innovation to fulfil fluctuating needs of consumers (Si et al., 2006; Ares et al., 2010). Now a day's food habit focuses on foods search with dual purposes, health benefits beyond traditional nutrition and a hygienically 
safe food (Özer and Kirmaci, 2010). In fermented dairy products addition of live beneficial microorganisms and prebiotics, which have potentials to modulate various biological functions of host gained tremendous momentum in last few decades. They are termed as probiotics; "live microorganisms which, when administered in adequate amounts confers health benefits" (FAO/WHO, 2002) whereas prebiotic is defined as "a non-digestible food ingredient that beneficially affects the host by selectively stimulating the growth and/or activity of one or a limited number of bacteria in the colon" (Schrezenmeir and deVrese, 2001).

Prebiotics are non-digestible oligosaccharides that support growth of probiotics specifically includes inulin, maltodextrins FOS, GOS etc. There are several documented health benefits conferred in the host upon regular consumption and has been popular subjects of review (Marco et al., 2017; Anand et al., 2016). Combining both as new approach, potential synergy of prebiotics and probiotics called 'synbiotics' in functional food research are used (Anand et al., 2017; Likotrifiti et al., 2015). Synbiotics have reportedly enhanced probiotics survivability during storage, gastrointestinal transit as well as colonisation on intestinal epithelial cells (Kolida and Gibson, 2011). India is known for its ancient civilisation and renowned for traditional medicinal knowledge, 'Ayurveda' unparallel in the world for its minimum side effects as compared to allopathic drugs. Historically, people are aware of antimicrobial and health beneficial potentials. Almost $70 \%$ of the world's population and $85 \%$ population of developing countries depend on traditional knowledge of their health needs. Hygienic awareness towards green consumerism, but ineffective elimination of pathogens and microbial spoilages leads to development and use of alternate techniques such as incorporation of naturally derived antimicrobial ingredients like essential oils (EOs). They also have Generally Regarded as Safe (GRAS) status and their broad spectrum inhibiting action against both Gram-positive and Gram negative microorganisms are gaining attention for its applicability in food and dairy products (Burt, 2004). Amongst herbal treasure of India Tulsi (Ocimum sanctum) has antimicrobial potentials against food spoilage and pathogenic bacteria ( $\mathrm{Si}$ et al., 2006). Moreover, shift in consumers towards foods with limited or no synthetic or chemical preservatives gave momentum for exploration of naturally occurring antimicrobials for food preservation and to fight microbial resistance to chemical preservatives (Sharma et al., 2014). Hence, addition of herbal extracts or essential oils could be an effective approach to meet requirements and also health benefits (Burt and Reinders, 2003; Burt, 2004). Besides being effective natural antimicrobial EO also known for various health benefits such as anticarcinogenic and anti-hypersensitivity (Rodríguez et al., 2009). There are quite a few reports available on utilisation of herbs or essential oils in fermented dairy foods (Mendoza-Yepes et al., 1997; Ayar, 2002; Burt, 2004). Although, it is highly desirable that probiotics and essential oil must be compatible and confer health benefit without any adverse effect on sensory attributes of product. This report describes prebiotic selection for probiotic starters, compatibility, product preparation physico-chemical, and sensory studies of synbiotic yoghurt with essential oil.

\section{Materials and Methods}

\section{Microorganisms}

Putative probiotic yogurt cultures Lactobacillus bulgaricus Lb-2 and Streptococcus thermophilus ST-1 (lab isolates isolated from dairy products) were activated 
on M17 and MRS agar (Himedia Labs Ltd, Mumbai, India) respectively by overnight incubation at $37^{\circ} \mathrm{C}$. Cultures were stored below $7^{\circ} \mathrm{C}$ in litmus milk and revived once in fortnight. All the bacterial cultures were also activated and maintained in glycerol stocks at $-80 \pm 1^{\circ} \mathrm{C}$ containing $20 \%$ glycerol.

Milk, essential oil, prebiotics and chemicals

Fresh buffalo milk was collected from cattle yard of National Dairy Research Institute, Karnal, Haryana. Skim milk powder for standardisation was from Modern Dairies Pvt. Ltd. Karnal, India. Essential oil ( Ocimum sanctum) was procured from Moksha products, New Delhi. Inulin and maltodextrin from Orafti Tienan, Belgium through S.A. Pharmachem Pvt. Ltd. Mumbai, India and stored at ambient temperature in dark place. Other chemicals used in study were procured from Merck ${ }^{\circledR}$ Chemicals.

\section{Prebiotics selection}

To select prebiotic the effect of inulin and maltodextrin on growth kinetics of probiotic yoghurt cultures was seen, carbohydrate free MRS/M-17 broth was used as basal growth medium. The basal medium was dispensed in $20 \mathrm{ml}$ volume in $50 \mathrm{ml}$ conical flasks and supplemented with varied concentrations of inulin and maltodextrin $(0.5,1,3$ and 5 percent w/v). The basal medium without any prebiotics was used as control. All the flasks were inoculated with overnight grown culture of L. bulgaricus LB-2 and S. thermophilus ST1 atone percent separately. Aliquots were withdrawn at $6 \mathrm{~h}$ time interval upto $24 \mathrm{~h}$ at $37^{\circ} \mathrm{C}$. The samples were analysed for $\mathrm{pH}$ and viable counts by plating on selective media. The colony counts were observed after incubating the plates at $37^{\circ} \mathrm{C} / 24 \mathrm{~h}$. Specific growth rate $(\mu)$ and mean doubling time $\left(T_{d}\right)$ were calculated as described by (Shin et al., 2000). Specific growth rate $(\mu)$ for each culture was calculated using the following equation: $\mu=\left(\ln X_{2}-\ln X_{1}\right) /\left(t_{1}-t_{2}\right)$, where $X_{2}$ and $X_{1}$ are the cell density at time $t_{2}$ and $t_{1}$. Mean doubling time $\left(\mathrm{T}_{\mathrm{d}}\right)$ was calculated as: $\mathrm{T}_{\mathrm{d}}$ $=\ln 2 / \mu$.

\section{Product preparation}

Fresh buffalo milk upon standardisation (3.5\% fat; $13 \%$ MSNF; $6.9 \mathrm{pH})$ used for yogurt preparation by following the method followed by Raju and Pal (2009). Initially prebiotic was added to milk at $45^{\circ} \mathrm{C}$ followed by homogenisation $\left(2500 \mathrm{psi} 1^{\text {st }}\right.$ stage and $500 \mathrm{psi}$ $2^{\text {nd }}$ stage). Milk was heated at $85^{\circ} \mathrm{C}$ for 30 min, cooled at $42^{\circ} \mathrm{C}$ and inoculated with yogurt cultures each at $0.5 \%$ rate followed by EO addition. Upon mixing filled in polystyrene cups and incubation was carried out $41 \pm 1^{\circ} \mathrm{C}$ for about $5 \mathrm{~h}$. Once desired acidity is achieved, cups were transferred to refrigerator $\left(5 \pm 1^{\circ} \mathrm{C}\right)$ for further analysis.

\section{Effect of EO on yogurt culture activity}

Diverse concentrations of essential oils (0.5, $0.8,1,1.5$ and $2 \mu \mathrm{L} / \mathrm{mL}$ ) in milk with inulin (after selection) was studied with culture inoculations at 1, 2, 3 and 4\%. Incubation was carried out at $41 \pm 1^{\circ} \mathrm{C}$ and measurements were taken for curd setting time, $\mathrm{pH}$ and titratable acidity.

\section{Effect of EO addition on quality of product}

Three different batches of yogurt, B1 with $0.5 \%$ EO, B2 with $0.8 \%$ EO and one batch with no EO were prepared and stored at refrigerator $\left(5 \pm 1^{\circ} \mathrm{C}\right)$ to take further measurements.

\section{Analysis of product}

In the present study, quality of the product has been assessed by analysing the physicochemical properties, sensory attributes and 
microbiological analysis by standard plate count method(Giusti et al., 2008).

\section{pH}

The $\mathrm{pH}$ values of product samples were measured using a digital $\mathrm{pH}$ meter $(\mathrm{pH}$ scan, $\mathrm{BNC}$, India) fitted with a standard, combined electrode. Instrument was calibrated with $\mathrm{pH} 4$ and $\mathrm{pH} 9$ buffer solutions prior to use.

\section{Acidity}

The titratable acidity in terms of percent lactic acid was determined. In this $10 \mathrm{~g}$ of sample was taken in a porcelain dish and homogenous mixture was prepared by adding $10 \mathrm{ml}$ distilled water followed by addition of $1 \mathrm{ml}$ of $0.5 \%$ phenolphthalein indicator.

This was titrated against $0.1 \mathrm{~N}$ sodium hydroxide by continuously stirring till pale pink colour disappeared.

\section{Synersis}

Synersis was measured by siphon method as described by Lucey (2001). In this case, after about $20 \mathrm{~h}$ storage under refrigeration (below $7^{\circ} \mathrm{C}$ ), cups filled with $80 \mathrm{ml}$ of synbiotic herbal yogurt was tempered at $25^{\circ} \mathrm{C}$ and kept inclined at $45^{\circ}$ angle. Using syringe the siphoned whey was considered as synersis and expressed as percentage of millilitres $(\mathrm{mL})$ of whey over initial volume of product sample.

\section{Sensory analysis}

Sensory evaluation of the developed product was carried out by the expert panel comprised of six discriminative and communicative judges. They were not trained for synbiotic yogurt with essential oil but were dairy professionals with adequate knowledge about sensory evaluation and product attributes. The cups of product were drawn at random from the refrigerator just before serving for sensory evaluation. All the samples were evaluated for flavour, body and texture, acidity colour and appearance and overall acceptability on 100 point scale as described by Ranganathan and Gupta (1987).

\section{Yoghurt bacterial count}

Product was stored at refrigerator (below $7^{\circ} \mathrm{C}$ ) for 21 days and representative sample drawn from each lot at 3 days intervals. Surface portion $(1 / 2$ inch) was scrapped out with sterile spatula and a homogenous mixture was prepared. Viable probiotic cell counts of both bacteria was determined by plating serial dilutions on selective media and incubating at $37^{\circ} \mathrm{C}$ for $48 \mathrm{~h}$.

\section{Antioxidant property and phenol content}

Antioxidant capacity assay was carried out by the ABTS [ 2, 2'-Azinobis (3-ethylbenzothiazoline)-6-sulfonic acid] diammonium salt method (Re et al., 1999). ABTS stock solution was prepared by dissolving $19.2 \mathrm{mg}$ of ABTS in $5 \mathrm{ml}$ double distilled water followed by addition of $88 \mu 1$ of potassium persulphate solution $(140 \mathrm{mM})$.

The mixture was kept in dark amber color bottle for 12-16 $\mathrm{h}$ for production of free radicals. For the study ABTS solution were diluted to an absorbance of $7.00 \pm 0.02$ at $734 \mathrm{~nm}$. ABTS $(3 \mathrm{ml})$ working solution made with PBS (pH 7.4) was added to cuvette $(3 \mathrm{ml}$ capacity) and absorbance adjusted to $0.7 \pm 0.02$ against the buffer. $4 \mu \mathrm{l} / \mathrm{ml}$ of sample (cell free supernatant) was added to ABTS working solution as well as in the blank. The contents were mixed for 5 seconds and change in absorbance at $734 \mathrm{~nm}$ was recorded over 10 min using double beam spectrophotometer (Shimadzu UV 2550). The results were expressed as $\mu \mathrm{mol}$ trolox equivalent / L. 
Total phenolic content of probiotic, synbiotic and synbiotic herbal yoghurt were determined by Folin Ciocalteu method (Kahkonen et al., 1999). Appropriately diluted $400 \mu 1$ of sample/ gallic acid standard ( $1 \mathrm{mg} / \mathrm{ml}$ in ethanol) was taken in a test tube. Added $2000 \mu 1$ of diluted Folin-Ciocalteu reagent $(0.2 \mathrm{~N})$ to it and mixed with vortex mixer. After $3 \mathrm{~min}, 1600 \mu \mathrm{l}$ of $\mathrm{Na}_{2} \mathrm{Co}_{3}(7.5 \%$ w/v) solution was added and incubated under dark at room temperature for $30 \mathrm{~min}$. For blank preparation $400 \mu \mathrm{l}$ of distilled water was taken instead of sample. The absorbance of the samples was measured against blank at $765 \mathrm{~nm}$ using double beam spectrophotometer (Shimadzu UV 2550).

\section{Statistical analysis}

The results were expressed as mean \pm standard deviation. Software programs such as MSExcel software (version 2007of Microsoft $^{\circledR}$, USA) and SAS (SAS Institute Inc.USA) were used to test significance by analysis of variance (ANOVA).

\section{Results and Discussion}

\section{Selection of prebiotics}

Probiotic yogurt cultures were grown in broth supplemented prebiotic carbohydrates as carbon source.Increase in growth kinetics of both cultures was observed in broth supplemented with oligosaccharides. However, growth kinetics in terms of specific growth rate doubling time and $\mathrm{pH}$ was varied with varied supplementations of prebiotics. Interestingly, both the cultures grew well on inulin supplementation.

Two prebiotics i.e. inulin and maltodextrin were evaluated for their effect on growth kinetics of probiotic yoghurt cultures w.r.t. change in log count, specific growth rate $(\mu)$, and doubling time (Td). The growth kinetics data have been depicted in Tables 1 and 2 .
Results of effect of prebiotics on growth kinetics showed that increased level of inulin and maltodextrin upto $3 \%(\mathrm{w} / \mathrm{v})$ improved changes in log count and specific growth rate, which in turn reduces doubling time. The observation indicate an increment in count, specific growth rate and reduction in doubling time of L.bulgaricus LB-2 in presence of varied concentrations of inulin and maltodextrin. The maximum increase in change in $\log \mathrm{cfu}$ value $(1.78 \log \mathrm{cfu} / \mathrm{ml})$, growth rate $\left(0.683 \mathrm{~h}^{-1}\right)$ and corresponding minimum doubling time $\left(\mathrm{T}_{\mathrm{d}}\right)(1.01 \mathrm{~h})$ was observed at $3 \%$ concentration of inulin during the first $6 \mathrm{~h}$ of the incubation period. The increased growth rate of the organism during the first $6 \mathrm{~h}$ can be attributed to the presence of other mono saccharides in the prebiotic.

Marked difference was observed during 6-12 h of time interval between the growth at $0.5,1,3$ and 5 percent even though the maximum growth rate was recorded at $3 \%$ of inulin. The specific growth rate varied from $0.35-0.43 h^{-1}$ and the doubling time ranged from 1.58 to $1.96 \mathrm{~h}$ during this period in case of inulin. There was a notable difference in the growth rate during the 12 to $18 \mathrm{~h}$ interval, with the maximum growth rate $\left(0.39 \mathrm{~h}^{-1}\right)$.

The doubling time $\left(T_{d}\right)$ was also recorded a minimum value $(1.73 \mathrm{~h})$ at the same level of inulin and maltodextrin. The growth of the organism during the last $6 \mathrm{~h}$ was very much reduced with the specific growth rate ranging from 0.12 to $0.24 \mathrm{~h}^{-1}$ and doubling time $\left(\mathrm{T}_{\mathrm{d}}\right)$ ranging from 7.53-15.07 $\mathrm{h}$ which indicates that the organism has approached the stationary phase. Almost a similar trend was observed with maltodextrin. The specific growth rate ranging from $0.43-0.54 \mathrm{~h}^{-1}$ to 1.27-1.58 $\mathrm{h}^{-1}$ during $0-6 \mathrm{~h}$ of incubation. The change in log count and specific growth rate were least at $18-24 \mathrm{~h}$ incubation. The doubling time ranged from $11.28-36.93 \mathrm{~h}$ a drastic change in $T_{d}$ was observed after $12-18 \mathrm{~h}$ of 
incubation. The difference could be explained as the fact that the optimum concentration of prebiotics may be strain dependent.

The growth kinetics of $S$. thermophilus ST-1, at different concentration of inulin and maltodextrin was presented in Table 2. The observation showed a gradual decrease in growth of probiotic $S$. thermophilus ST-1 during 6-24h of incubation period. A change in $\log$ value was higher during $0-6 \mathrm{~h}$ at $1 \%$ level of inulin; however, the change was not significant in case of maltodextrin. This change was minimum at $18-24 \mathrm{~h}$ of incubation in both inulin and maltodextrin at all the levels. The specific growth rate ranged from 0.391 to 0.430 at $1 \%$ level of inulin, these values ranged from $0.243-0.361$ and 0.169 $0.246 \mathrm{~h}^{-1}$ for $6-12 \mathrm{~h}$ and $12-18 \mathrm{~h}$ respectively. Similar trend was noticed with maltodextrin at these concentrations during the incubation period. The doubling time reduced to 1.61 from $1.84 \mathrm{~h}$ of control indicated that inulin at $1 \%$ level favours the growth of $S$. thermophilus ST-1. The results on doubling time indicated reduction upto 6-18 $\mathrm{h}$ of incubation. The increment in incubation period also increased the doubling time. The highest doubling time was observed during 18-24 h of incubation, however, at $1 \%$ level, this was 6.45 and $3.22 \mathrm{~h}$ in case of inulin and maltodextrin, respectively for S.thermophilus ST-1. The doubling time was also recorded to be least at $3 \%$ of prebiotics during the entire interval. Even during 18-24h interval, 3\% inulin and maltodextrin were able to retain sufficient growth of the organism as compared to other concentrations. In general, the maximum growth rate and the minimum doubling time were recorded at $3 \%$ inulin. The growth of probiotics strain at $5 \%$ concentration was slightly less than $3 \%$ suggests that increase in concentration did not result in further increase in specific growth rate and reduction in doubling time. The above results suggest that $3 \%$ concentration of inulin to be optimum for stimulating the growth of yoghurt culture L. bulgaricus LB-2 and $S$. thermophilus ST-1. Among the various oligosaccharides FOS have been most extensively studied prebiotics and provided the best evidence of prebiotic effects in humans (Crittenden and Playne, 1996). Shin et al., (2000) demonstrated decrease in doubling time or increased activity of bifidobacteria with increase in concentration of FOS as oligosaccharide, and maximum activity was observed at 5\%. Desai et al., (2004) evaluated doubling time of 7 lactobacilli strains in presence of different prebiotics added to skim milk and found significant decrease in values where fructans like inulin and raftilose were present.

\section{Effect of EO on yogurt culture activity}

The compatibility of probiotic yoghurt cultures with varying concentration of Ocimum sanctum $(0.5,1.0,1.5$ and $2.0 \mu 1 / \mathrm{ml})$ were determined in milk system by measuring change in $\mathrm{pH}$, titratable acidity and curd settling time. The observations on these aspects have been presented in Table 3 .

The observations showed increased concentration results in decrease of $\mathrm{pH}$ with increase inoculum level of probiotic cultures. The increased concentration of essential oil requires longer time to produce quality product. The curd settling time of $6 \mathrm{~h}$ was observed at $1.5 \mu \mathrm{l} / \mathrm{ml}$ of essential oil at $1 \%$ inoculum size. The increment in inoculum level upto $4 \%$ reduced the curd settling time to $5 \mathrm{~h}$ at $1.5 \mu \mathrm{l} / \mathrm{ml}$ EO concentration. Whereas, titratable acidity remains $1.2 \% \mathrm{LA}$ at all culture concentrations. Setting time of $5 \mathrm{~h}$ was recorded at $0.5 \mu \mathrm{l} / \mathrm{ml}$ concentration with titratable acidity of $0.88 \%$ LA. Therefore, $1 \%$ inoculum size and $0.5 \mu \mathrm{l} / \mathrm{ml}$ of $\mathrm{EO}$ were selected for development of synbiotic herbal yoghurt. Lactic acid bacteria are often known among the resistant species against herbal antimicrobial agents (Lemay et al., 2002). 
Table.1 Effect of prebiotics on specific growth rate $(\mu)$ and doubling time $\left(\mathrm{T}_{\mathrm{d}}\right)$ of L.bulgaricus LB-2

\begin{tabular}{|c|c|c|c|c|c|c|c|c|}
\hline \multirow{3}{*}{$\begin{array}{c}\text { Prebiotic } \\
\text { conc. } \\
(\% \mathrm{w} / \mathrm{v})\end{array}$} & \multicolumn{8}{|c|}{ Time interval (h) } \\
\hline & \multicolumn{2}{|c|}{$0-6$} & \multicolumn{2}{|c|}{$6-12$} & \multicolumn{2}{|c|}{$12-18$} & \multicolumn{2}{|c|}{$18-24$} \\
\hline & $\mu\left(h^{-1}\right)$ & $\mathrm{T}_{\mathrm{d}}(\mathrm{h})$ & $\mu\left(h^{-1}\right)$ & $\mathrm{T}_{\mathrm{d}}(\mathrm{h})$ & $\mu\left(h^{-1}\right)$ & $\mathrm{T}_{\mathrm{d}}(\mathrm{h})$ & $\mu\left(h^{-1}\right)$ & $\mathrm{T}_{\mathrm{d}}(\mathrm{h})$ \\
\hline \multicolumn{9}{|c|}{ Inulin } \\
\hline Control & $0.38 \pm 0.02$ & $1.79 \pm 0.14$ & $0.23 \pm 0.04$ & $2.92 \pm 0.16$ & $0.12 \pm 0.02$ & $5.82 \pm 0.2$ & $0.01 \pm 0.01$ & $46.20 \pm 2.82$ \\
\hline 0.5 & $0.57 \pm 0.01$ & $1.21 \pm 0.11$ & $0.35 \pm 0.01$ & $1.96 \pm 0.16$ & $0.12 \pm 0.04$ & $3.47 \pm 0.8$ & $0.04 \pm 0.01$ & $15.07 \pm 1.15$ \\
\hline 1.0 & $0.59 \pm 0.01$ & $1.17 \pm 0.16$ & $0.36 \pm 0.02$ & $1.92 \pm 0.14$ & $0.24 \pm 0.05$ & $2.82 \pm 0.3$ & $0.08 \pm 0.02$ & $8.25 \pm 1.14$ \\
\hline 3.0 & $0.68 \pm 0.03$ & $1.02 \pm 0.18$ & $0.43 \pm 0.02$ & $1.58 \pm 0.17$ & $0.39 \pm 0.02$ & $1.73 \pm 0.9$ & $0.09 \pm 0.04$ & $7.53 \pm 1.20$ \\
\hline 5.0 & $0.62 \pm 0.07$ & $1.12 \pm 0.11$ & $0.39 \pm 0.05$ & $1.76 \pm 0.16$ & $0.29 \pm 0.02$ & $2.32 \pm 0.1$ & $0.04 \pm 0.01$ & $15.06 \pm 1.8$ \\
\hline \multicolumn{9}{|c|}{ Maltodextrin } \\
\hline 0.5 & $0.43 \pm 0.01$ & $1.58 \pm 0.17$ & $0.25 \pm 0.05$ & $2.82 \pm 0.14$ & $0.09 \pm 0.01$ & $7.53 \pm 0.4$ & $0.01 \pm 0.01$ & $36.28 \pm 1.6$ \\
\hline 1.0 & $0.52 \pm 0.03$ & $1.31 \pm 0.14$ & $0.26 \pm 0.02$ & $2.66 \pm 0.18$ & $0.11 \pm 0.01$ & $6.24 \pm 0.13$ & $0.04 \pm 0.01$ & $16.25 \pm 1.20$ \\
\hline 3.0 & $0.54 \pm 0.05$ & $1.27 \pm 0.16$ & $0.46 \pm 0.06$ & $1.48 \pm 0.15$ & $0.21 \pm 0.03$ & $3.24 \pm 0.08$ & $0.06 \pm 0.05$ & $11.28 \pm 1.71$ \\
\hline 5.0 & $0.51 \pm 0.02$ & $1.36 \pm 0.13$ & $0.39 \pm 0.02$ & $1.73 \pm 0.12$ & $0.19 \pm 0.09$ & $4.12 \pm 0.09$ & $0.05 \pm 0.02$ & $13.92 \pm 1.23$ \\
\hline
\end{tabular}

Data are presented as Mean \pm SD $(n=3)$.

Table.2 Effect of prebiotics on specific growth rate $(\mu)$ and doubling time $\left(\mathrm{T}_{\mathrm{d}}\right)$ of $\mathrm{S}$. thermophilus $\mathrm{ST}-1$

\begin{tabular}{|c|c|c|c|c|c|c|c|c|}
\hline \multirow{3}{*}{$\begin{array}{l}\text { Prebiotic } \\
\text { conc. } \\
(\% \mathrm{w} / \mathrm{v})\end{array}$} & \multicolumn{8}{|c|}{ Time interval (h) } \\
\hline & \multicolumn{2}{|l|}{$0-6$} & \multicolumn{2}{|l|}{$6-12$} & \multicolumn{2}{|l|}{$12-18$} & \multicolumn{2}{|l|}{$18-24$} \\
\hline & $\mu\left(h^{-1}\right)$ & $\mathrm{T}_{\mathrm{d}}(\mathrm{h})$ & $\mu\left(h^{-1}\right)$ & $\mathrm{T}_{\mathrm{d}}(\mathrm{h})$ & $\mu\left(h^{-1}\right)$ & $\mathrm{T}_{\mathrm{d}}(\mathrm{h})$ & $\mu\left(h^{-1}\right)$ & $\mathrm{T}_{\mathrm{d}}(\mathrm{h})$ \\
\hline \multicolumn{9}{|c|}{ Inulin } \\
\hline Control & $0.37 \pm 0.01$ & $1.84 \pm 0.9$ & $0.19 \pm 0.04$ & $3.47 \pm 1.4$ & $0.16 \pm 0.04$ & $4.30 \pm 1.1$ & $0.03 \pm 0.04$ & $22.57 \pm 1.9$ \\
\hline 0.5 & $0.39 \pm 0.02$ & $1.77 \pm 0.7$ & $0.25 \pm 0.02$ & $2.74 \pm 1.2$ & $0.16 \pm 0.02$ & $4.11 \pm 1.6$ & $0.04 \pm 0.01$ & $18.09 \pm 1.3$ \\
\hline 1.0 & $0.43 \pm 0.04$ & $1.61 \pm 0.6$ & $0.36 \pm 0.06$ & $1.92 \pm 1.7$ & $0.24 \pm 0.07$ & $2.82 \pm 0.9$ & $0.10 \pm 0.02$ & $6.45 \pm 0.9$ \\
\hline 3.0 & $0.42 \pm 0.03$ & $1.64 \pm 0.6$ & $0.27 \pm 0.02$ & $2.50 \pm 1.6$ & $0.21 \pm 0.05$ & $3.22 \pm 0.6$ & $0.08 \pm 0.03$ & $8.21 \pm 0.8$ \\
\hline 5.0 & $0.39 \pm 0.02$ & $1.73 \pm 0.9$ & $0.24 \pm 0.01$ & $2.82 \pm 1.1$ & $0.19 \pm 0.01$ & $3.61 \pm 1.4$ & $0.06 \pm 0.01$ & $11.28 \pm 1.2$ \\
\hline \multicolumn{9}{|c|}{ Maltodextrin } \\
\hline 0.5 & $0.37 \pm 0.02$ & $1.83 \pm 0.31$ & $0.30 \pm 0.02$ & $2.26 \pm 0.7$ & $0.16 \pm 0.03$ & $4.30 \pm 1.4$ & $0.09 \pm 0.01$ & $7.23 \pm 0.2$ \\
\hline 1.0 & $0.47 \pm 0.07$ & $1.46 \pm 0.09$ & $0.38 \pm 0.03$ & $1.81 \pm 0.4$ & $0.34 \pm 0.05$ & $2.05 \pm 0.09$ & $0.21 \pm 0.01$ & $3.22 \pm 0.6$ \\
\hline 3.0 & $0.45 \pm 0.05$ & $1.53 \pm 0.06$ & $0.41 \pm 0.04$ & $1.67 \pm 0.9$ & $0.34 \pm 0.01$ & $2.01 \pm 0.08$ & $0.23 \pm 0.01$ & $3.01 \pm 0.6$ \\
\hline 5.0 & $0.39 \pm 0.02$ & $1.74 \pm 0.07$ & $0.34 \pm 0.06$ & $2.00 \pm 0.1$ & $0.22 \pm 0.02$ & $3.11 \pm 0.05$ & $0.13 \pm 0.02$ & $5.32 \pm 0.4$ \\
\hline
\end{tabular}


Table.3 Compatibility of probiotic yoghurt cultures with Ocimum sanctum essential oil in yogurt preparation with $3 \%$

\begin{tabular}{|c|c|c|c|c|c|c|}
\hline \multirow{2}{*}{$\begin{array}{l}\text { Culture levels } \\
(\% \text { v/v) }\end{array}$} & \multirow{2}{*}{$\begin{array}{l}\text { Quality } \\
\text { attributes }\end{array}$} & \multicolumn{5}{|c|}{ Essential oil concentration $(\mu \mathrm{L} / \mathrm{mL})$} \\
\hline & & Control (0) & 0.5 & 1 & 1.5 & 2 \\
\hline \multirow{3}{*}{1} & pH & $4.54 \pm 0.006$ & $4.51 \pm 0.01$ & $4.22 \pm 0.01$ & $4.06 \pm 0.01$ & $4.00 \pm 0.01$ \\
\hline & TA (\%LA) & $0.84 \pm 0.006$ & $0.88 \pm 0.01$ & $1.05 \pm 0.01$ & $1.18 \pm 0.01$ & $1.16 \pm 0.01$ \\
\hline & CST (h) & 5.50 & 5.0 & 5.0 & 6.0 & $* *$ \\
\hline \multirow{3}{*}{2} & pH & $4.50 \pm 0.01$ & $4.56 \pm 0.006$ & $4.14 \pm 0.01$ & $4.02 \pm 0.01$ & $3.34 \pm 0.006$ \\
\hline & TA (\%LA) & $0.88 \pm 0.006$ & $0.92 \pm 0.006$ & $1.08 \pm 0.01$ & $1.22 \pm 0.011$ & $1.14 \pm 0.01$ \\
\hline & CST (h) & 4.50 & $4.5-5$ & 6.00 & 6.00 & $* *$ \\
\hline \multirow{3}{*}{3} & pH & $4.36 \pm 0.01$ & $4.32 \pm 0.2$ & $4.10 \pm 0.09$ & $4.08 \pm 0.01$ & $3.25 \pm 0.03$ \\
\hline & TA (\%LA) & $0.98 \pm 0.01$ & $0.96 \pm 0.006$ & $1.20 \pm 0.05$ & $1.22 \pm 0.01$ & $1.24 \pm 0.01$ \\
\hline & CST (h) & 4.00 & 4.50 & 5.00 & 5.50 & $* *$ \\
\hline \multirow{3}{*}{4} & pH & $4.24 \pm 0.006$ & $4.1 \pm 0.01$ & $3.98 \pm 0.01$ & $3.96 \pm 0.01$ & $3.20 \pm 0.006$ \\
\hline & TA (\%LA) & $1.02 \pm 0.01$ & $1.15 \pm 0.01$ & $1.22 \pm 0.01$ & $1.28 \pm 0.011$ & $1.26 \pm 0.01$ \\
\hline & CST (h) & 4.00 & 4.50 & 5.00 & 5.00 & 6.00 \\
\hline
\end{tabular}

** Milk curdled after $24 \mathrm{~h}$ incubation; CST - Curd setting time

\begin{tabular}{|c|c|c|c|}
\hline \multicolumn{4}{|c|}{ Physico-chemical Properties } \\
\hline Parameters & Control & $0.5(\mu \mathbf{L} / \mathbf{m L})$ & $0.8(\mu \mathrm{L} / \mathrm{mL})$ \\
\hline Titratable acidity (\%LA) & $0.90 \pm 0.01$ & $0.92 \pm 0.001$ & $0.94 \pm 0.001$ \\
\hline pH & $4.45 \pm 0.006$ & $4.42 \pm 0.006$ & $4.41 \pm 0.01$ \\
\hline Synersis (\%) & $0.60 \pm 0.10$ & $0.73 \pm 0.057$ & $0.93 \pm 0.057$ \\
\hline \multicolumn{4}{|c|}{ Sensory attributes } \\
\hline Flavour & $40.99 \pm 1.349^{\mathrm{a}}$ & $43.44 \pm 1.042^{b}$ & $38.5 \pm 1.098^{\mathrm{c}}$ \\
\hline Body and texture & $27.77 \pm 1.309^{\mathrm{ns}}$ & $27 \pm 0.840^{\mathrm{ns}}$ & $28.44 \pm 1.097^{\mathrm{ns}}$ \\
\hline Acidity & $8.33 \pm 1.085^{\mathrm{a}}$ & $9.0 \pm 0.686^{b}$ & $8.61 \pm 0.979^{c}$ \\
\hline Colour and appearance & $8.33 \pm 1.056^{\mathrm{a}}$ & $9.27 \pm 0.669^{b}$ & $9.5 \pm 0.618^{c}$ \\
\hline Overall acceptability & $85.72 \pm 3.214^{\mathrm{a}}$ & $90.22 \pm 2.238^{b}$ & $84.94 \pm 2.55^{c}$ \\
\hline
\end{tabular}




\section{Table.5 Antioxidative activity and phenolic content of probiotic, synbiotic and synbiotic herbal}

\section{yoghurt}

\begin{tabular}{|l|c|c|c|}
\hline Type of yoghurt & $\begin{array}{c}\text { Essential oil } \\
\text { concentration } \\
(\boldsymbol{\mu l} / \mathbf{m l})\end{array}$ & $\begin{array}{c}\text { Antioxidant activity } \\
(\boldsymbol{\mu m o l ~ T r o l o x} \\
\text { equivalent / litre) }\end{array}$ & $\begin{array}{c}\text { Total phenol } \\
\text { content in } \\
(\mathbf{m g} \text { GAE/100ml) }\end{array}$ \\
\hline Probiotic yoghurt & 0 & $320.5 \pm 9.6$ & $3.7 \pm 0.090$ \\
\hline Synbiotic yoghurt & 0 & $476.7 \pm 5.4$ & $3.6 \pm 0.033$ \\
\hline Synbiotic herbal yoghurt & 0.2 & $635.0 \pm 9.6$ & $4.8 \pm 0.038$ \\
\hline Synbiotic herbal yoghurt & 0.5 & $763.8 \pm 6.5$ & $6.9 \pm 0.025$ \\
\hline Synbiotic herbal yoghurt & 0.8 & $801.1 \pm 8.0$ & $7.8 \pm 0.025$ \\
\hline Synbiotic herbal yoghurt & 1.0 & $892.5 \pm 8.4$ & $8.3 \pm 0.012$ \\
\hline Data presented as Means \pm SD $(\mathbf{n}=\mathbf{6})$ & & & \\
\hline
\end{tabular}

Fig.1 Effect of storage period on survival of probiotic count in symbiotic herbal yoghurt

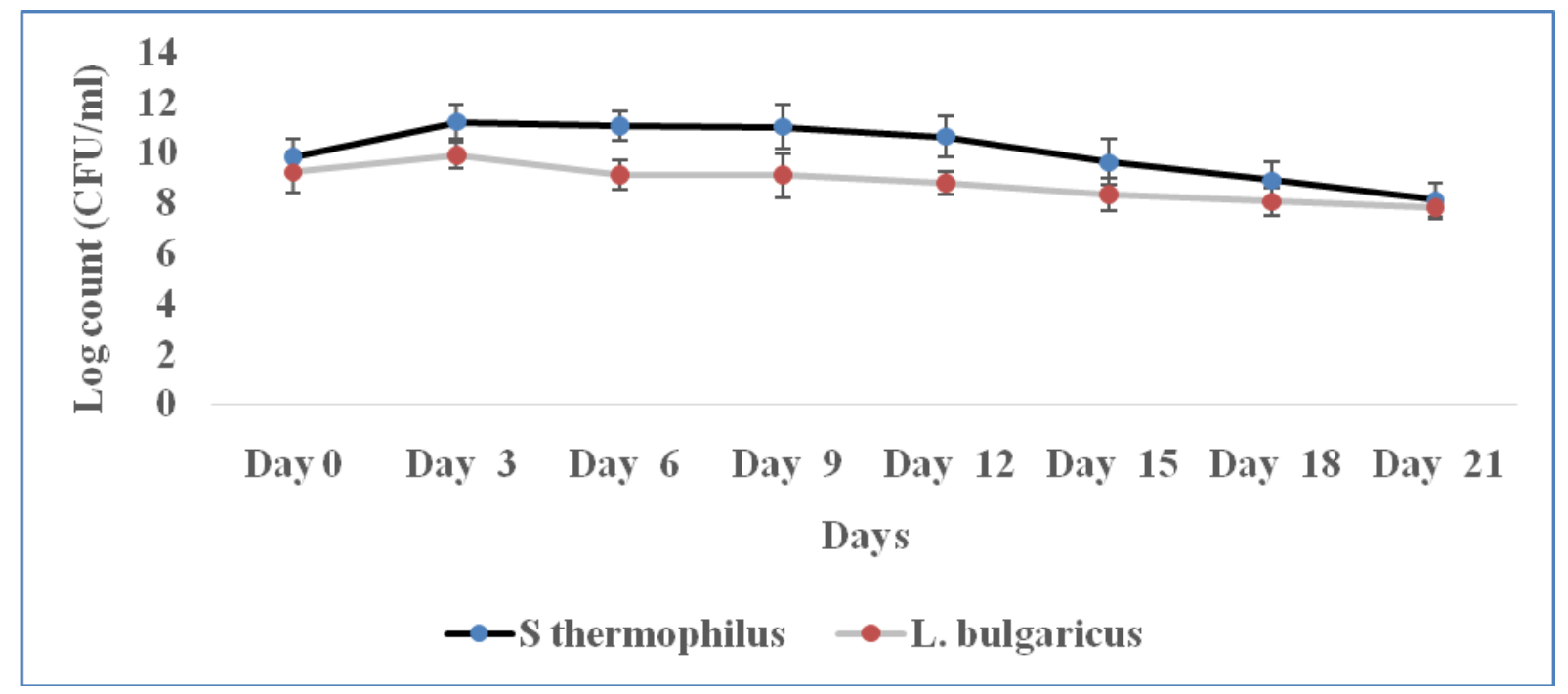

In a study by Anand et al., (2016), minimal inhibitory concentration of the starter cultures for dahi and yoghurt was recorded upto 1.8 $\mu \mathrm{l} / \mathrm{ml}$. Hence, increase curd settling time and low titratable acidity may be attributed to bacteriostatic effect at higher concentration $1.5-2.0 \mu \mathrm{l} / \mathrm{ml}$ of essential oil on probiotic bacteria.

\section{Effect of EO on titratable acidity, pH and synersis}

Acidity of product is one of the parameters that determine the product quality and acceptability. Synersis results and effect of
EO on titratable acidity are given in Table 4. There was increase in acidity but no synersis were observed with increase in EO concentrations. Synersis also termed as whey separation is deposition of whey on the surface of curd. Very less or negligible amount of whey expulsion was observed in yogurt and also increase in quantity of essential oil did not seem to affect synersis in the developed product. This may be attributed to ropy like substances ( $r$ ) production ability of one of yogurt cultures or might be influence on protein-protein interactions. Guzel-Seydim et al., ( 2005) observed 
decreased whey separation when culture $\mathrm{r}^{+}$ culture was used. However, slight increase in synersis was observed during storage period. There are quite a few reports on incorporation of EO in dairy or fermented dairy foods. Mahmoudi et al., ( 2014) also observed decrease in $\mathrm{pH}$ in Teucrium polium essential oil incorporated probiotic yoghurt. Same author also recorded increase in TA of yoghurt samples. Singh et al., (2011) also reported decrease in $\mathrm{pH}$ in presence of essential oils but found concentration of 1.0 $\mathrm{g} / \mathrm{l}$ of anise oil was not strong enough to down regulate yoghurt bacterial count below $10^{7} \mathrm{cfu} / \mathrm{ml}$ during 10 days storage period along with titratable acidity of $1 \%$ LA.

\section{Sensory attributes}

Scores for all the sensory attributes conducted on yogurts stored at below $7{ }^{\circ} \mathrm{C}$ are listed in Table 4. Decrease in scores was observed with increase in essential oil content. Significant differences $(\mathrm{P}<0.01)$ were observed between levels of EO. The scores in control to synbiotic yogurt with EO varied from 40.9 to 38.5 for flavour, 27.7 to 29.4 for body and texture, 8.61 to 8.33 for acidity and 8.94 to 9.5 for colour and appearance. However, EO level at $0.5 \%$ was scored good with overall acceptability score 90.22 showing better sensory attributes of product as rated by panellists. When ANOVA was applied between-panellists variations were non-significant $(\mathrm{P}>0.01)$ and found to be significant between panellist and samples. Tornambé et al., (2008) reportedly succeeded to study the effect of pasture plant EO addition in milk and found that lower concentration of $0.1 \mu \mathrm{L} / \mathrm{L}$ did not influence its sensory properties, whereas at higher concentration at $1.0 \mu \mathrm{L} / \mathrm{L}$, sensory properties were modified. A similar type of trend was also reported by Mahmoudi et al., (2014), adequate sensory attributes and higher acceptance at $40 \mathrm{ppm}$ of Tecurium polium EO with appropriated viability of probiotic Lactobacillus casei.

\section{Viability probiotic cultures}

The viable cell counts of yogurt bacteria in $\log$ values upto 21 days are reported in Figure 1 . There was a significant difference between the $0^{\text {th }}$ day and last day of count of control sample. The yogurt bacterial count increased slightly during first 3 days and decreased in subsequent days. The reduction in cell counts could be attributed to the possible moisture loss due to dehydration, increase in osmotic pressure or inhibitory effects of metabolic end products. The viable cell counts requirements for probiotic cell varies from $10^{6}-10^{8} \mathrm{cfu} / \mathrm{ml}$. The viable cell counts of both the strains present in yoghurt are found greater than $10^{6}$ $\mathrm{cfu} / \mathrm{ml}$. The observation was remain in agreement with probiotic cell viable counts up to 15 days of shelf life at below $7^{\circ} \mathrm{Cprepared}$ in presence of Mentha piperita and Ziziphora clinopodioides (Sarabai-Jamab and Niazmand 2009).

\section{Antioxidant property and phenol content}

Antioxidative activity of probiotic, synbiotic herbal yoghurts, was determined by ABTS method. Total phenolic content were determined by Folin Ciocalteu method (Kahkonen et al., 1999).The research findings have been presented in Table 5. The observations revealed a continuous increase in antioxidative activity with addition of prebiotic and essential oil of O. sanctum. The antioxidative property of synbiotic herbal yoghurt $(0.5 \mu 1 / \mathrm{ml}$ essential oil) was $763.80 \pm$ $6.55 \mu \mathrm{mol}$ trolox equivalents per litre. Further 
increment of essential oil upto $1 \mu \mathrm{l} / \mathrm{ml}$ of milk resulted in antioxidant activity of $892.50 \pm$ $28.43 \mu \mathrm{mol}$ trolox equivalents/L. The observation suggests that synbiotic product fortified with essential oil fortification could be utilized to manage oxidative stress. The observations on total phenolic content showed increment in essential oil concentration and prebiotics would result enhancement of inhibitory activity of probiotic yoghurt cultures toward food spoilage and pathogens. Total phenolic content of synbiotic herbal yoghurt $(0-5 \mu 1 / \mathrm{ml}$ essential oil) was $6.988 \pm$ $0.0254 \mathrm{mg}$ GAE/ $100 \mu \mathrm{l}$, as compared to probiotic yoghurt $(3.731 \pm 90 \mathrm{mg} \mathrm{GAE} / \mathrm{ml})$. The higher antioxidant activities and total phenol content in fermented products incorporated with herbal extracts were most likely to present due to phytochemical contents and as a result of microbial metabolic activities (Thompson et al., 2007; Ishikawa et al., 2002).

The new Tulsi (Ocimum sanctum) essential oil added synbiotic yogurt seems to be technologically viable with adequate numbers of probiotic bacteria. The product has also shown evidencing extended shelf life. Synbiotic yogurt with essential oil, by virtue of antioxidant and other properties can impart multi health benefits to consumers. However, further in vivo studies are required to claim the health benefits are under progress.

\section{Acknowledgments}

The authors thank the Director of ICARNDRI for supporting the work.

\section{References}

Anand, S., Grover, C. R., and Beniwal, A. 2016. Evaluation of Ocimum sanctum essential oil as potential preservative for fermented dairy products. Journal of Pure and Applied Microbiology, 10(4): 2763-2772.

Anand, S., Mandal, S., and Tomar, S. K. 2017. Effect of Lactobacillus rhamnosus NCDC 298 with FOS in combination on viability and toxin production of enterotoxigenic Escherichia coli. Probiotics and Antimicrobial Proteins, 22:1-7.

Anand, S., Mandal, S., Patil, P., and Tomar, S. K. 2016. Pathogen-induced secretory diarrhea and its prevention. European Journalof Clinical Microbiology and Infectious Diseases, 35(11): 1721-1739.

Ares, G., Giménez, A., and Deliza, R.2010.Influence of three non-sensory factors on consumer choice of functional yogurts over regular ones. Food Qualityand Preference, 21:361367.

Ayar, A. 2002. Effect of some herb essential oils on lipolysis in white cheese. Journal of Food Lipids, 9: 225-237.

Burt, S. A., andReinders, R. D. 2003. Antibacterial activity of selected plant essential oils against Escherichia coli O157:H7. Letters in Applied Microbiology, 36:162-167.

Burt, S. 2004. Essential oils: their antibacterial properties and potential applications in foods-a review. International Journal of Food Microbiology, 94: 223-253.

Crittenden, R.G., and Playne, M. 1996. Production, properties and applications of food-grade oligosaccharides. Trends in Food Science and Technology, 7(11):353-361.

Desai, A. R., Powell, I. B., and Shah, N. P.2004.Survival and activity of probiotic lactobacilli in skim milk containing prebiotics. Journal of Food Science, 69(3): FMS57-FMS60.

FAO/WHO. 2002. Guidelines for evaluation of probiotics in food. In report of a joint 
FAO/WHO working group on drafting guidelines for the evaluation of probiotics in food. London, Ontario, Canada, April 30 and May 1, 2002.

Giusti, A., Bignetti, E., and Cannella, C. 2008. Exploring New Frontiers in Total Food Quality Definition and Assessment: From Chemical to Neurochemical Properties. Food Bioprocess and Technology, 1:130-142.

Guzel-Seydim Z.B., Sezgin, E., and Seydim, A. C. 2005. Influences of exopolysaccharide producing cultures on the quality of plain set type yogurt. Food Control, 16: 205-209.

Ishikawa, T., Kudo, M., and Kitajima, J. 2002. Water-soluble constituents of dill. Chemical and Pharmceutical Bulletin, 50(4): 501-7.

Kahkonen, M. P., Hopia, A. I., Vuorela, H. J., Rauha, J. P., Pihlaja, K., Kujala, T. S., and Heinonen, M. 1999. Antioxidant activity of plant extracts containing phenolic compounds. Journal of Agriculture and Food Chemistry, 47(10): 3954-3962

Kolida, S., and Gibson, G. R. 2011. Synbiotics in Health and Disease. Annual Review Food Science and Technology, 2: 373-393.

Lemay, M. J., Choquette, P. J., Delaquis, C., Gariepy, N., Rodrigue N., and Saucier, L. 2002. Antimicrobial effect of natural preservatives in a cooked and acidified chicken meat model. International Journal of Food Microbiology, 78(3): 217-226.

Likotrafiti, E., Valavani, P., Argiriou, A., and Rhoades, J. 2015. In vitro evaluation of potential antimicrobial synbiotics using Lactobacillus kefiri isolated from kefir grains. International Dairy Journal, 45: 23-30.

Lucey, J. A. 2001. The relationship between rheological parameters and whey separation in milk gels. Food Hydrocolloids, 15: 603-608.

Mahmoudi, R., Zare, P., Hassanzadeh, P., and Nosratpour, S. 2014. Effect of Teucrium polium essential oil on the physicochemical and sensory properties of probiotic yoghurt. Journal of food processing and preservation, 38(3):880888.

Marco, M. L., Heeney, D., Binda, S., Cifelli, C. J., Cotter, P. D., Foligne, B., Gänzle, M., Kort, R., Pasin, G., Pihlanto, A., and Smid, E. J. 2017. Health benefits of fermented foods: microbiota and beyond. Current Opinion in Biotechnology, 44: 94-102.

Mendoza-Yepes, M. J., Sanchez-Hidalgo, L. E., Maertens, G., and Marin-Iniesta, F. 1997. Inhibition of listeria monocytogenes and other bacteria by a plant essential oil in Spanish soft cheese. Journal of Food Safety, 17:4755.

Özer, B. H., and Kirmaci, H. A. 2010. Functional milks and dairy beverages. International Journal of Dairy Technology, 63: 1-15.

Raju NP, Pal D ( 2009). The physicochemical, sensory, and textural properties of misti dahi prepared from reduced fat buffalo milk. Food Bioprocess Tech 2: 101-108.

Ranganadham, M., and Gupta, S. K. 1987. Sensory evaluation of dahi and yoghurt. Indian Dairyman, 39(10): 493-497.

Re, R., Pellegrini, N., Proteggente, A., Pannala, A., Yang, M., Rice-Evans, C. 1999. Antioxidant activity applying an improved ABTS radical cation decolorization assay. Free Radical Biology and Medicine, 26(9):12311237.

Rodríguez, H., Curiel, J. A., Landete, J. M., de las Rivas, B., de Felipe, F. L., Gómez-Cordovés, C., Mancheño, J.M., Munoz, R. 2009. Food phenolics and 
lactic acid bacteria. International Journal of Food Microbiology, 132:7990.

Sarabai-Jamab, M., and Niazmand, R. 2009. Effect of essential oil of Mentha piperita and Ziziphora clinopodioides on Lactobacillus acidophilusactivity as bioyogurt starter culture. American Eurasian Journal of Agriculture Environmental Science, 6: 129-131.

Sharma, P., Tomar, S. K., Goswami, P., Sangwan, V., and Singh, R. 2014. Antibiotic resistance among commercially available probiotics. Food Research International, 57: 176-195.

Shin, H. S., Lee, J. H., Pestka, J.J., and Ustunol, Z. 2000. Growth and viability of commercial Bifidobacterium spp in skim milk containing oligosaccharides and inulin. Journal of Food Science, 65(5): 884-887.
Si, W., Gong, J., Tsao, R., Zhou, T., Yu, H., Poppe, C., Johnson, R., and Du, Z. 2006. Antimicrobial activity of essential oils and structurally related synthetic food additives towards selected pathogenic and beneficial gut bacteria. Journal of Applied Microbiology, 100: 296-305.

Singh, G., Kapoor, I. P., and Singh, P. 2011. Effect of volatile oil and oleoresin of anise on the shelf life of yogurt. J Food Process and Preservation, 35(6): 778783.

Thompson, J. L., Lopetcharat, K., and Drake, M. 2007. Preferences for commercial strawberry drinkable yogurts among African American, Caucasian, and Hispanic consumers in the United States. Journal of Dairy Science, 90(11): 4974-87.

\section{How to cite this article:}

Santosh Anand, Manju Gaare, Priyanka Saini, Arun Beniwal and Chand Ram Grover. 2018. Synbiotic Yogurt Supplemented with Ocimum sanctum Essential Oil. Int.J.Curr.Microbiol.App.Sci. 7(03): 1250-1262. doi: https://doi.org/10.20546/ijcmas.2018.703.148 